Revista de Economia Política, vol. 20, nº 1 (77), pp. 96-123, janeiro-março/2000

\title{
A Nova Proposta de Reforma Tributária do Governo: Limites do Possível e Incertezas Envolvidas
}

\author{
The New Government Tax Reform Proposal: Limits \\ of the Possible and Uncertainties Involved
}

ROGÉRIO L. F. WERNECK*, * *

\begin{abstract}
RESUMO: No final de 1997, o governo brasileiro anunciou a primeira versão de uma reforma tributária que contemplava uma revisão completa da tributação indireta no país. Os impostos sobre o faturamento deveriam ser eliminados e a perda de receita resultante compensada por um novo IVA de base ampla coordenado pelo governo federal, que substituiria os atuais IVAs estaduais incoerentes e o imposto sobre serviços em grande parte mal administrado imposto pelos governos locais. Neste artigo, modelos de simulação são usados para estudar a consistência da reforma proposta e algumas de suas possíveis consequências. Uma estrutura de análise de risco é usada para sublinhar as incertezas mais importantes envolvidas.
\end{abstract}

PALAVRAS-CHAVE: Reforma tributária; tributação; incidência tributária; IVS; relações intergovernamentais.

ABSTRACT: In late 1997, the Brazilian government announced the first version of a tax reform contemplating a complete overhaul of the indirect taxation in the country. Turnover taxes were to be eliminated and the entailing loss of revenue compensated by a new federally coordinated broad-based VAT, that would replace the present incoherent state VATs and the largely mismanaged service tax imposed by local-governments. In this article, simulation models are used to study the consistency of the proposed reform and some of its possible consequences. A risk analysis framework is used to underline the most important uncertainties involved.

KEYWORDS: Tax reform; taxation; tax incident; VAT; intergovernmental relations.

JEL Classification: E22; E21.

\footnotetext{
* Professor do Departamento de Economia da Pontifícia Universidade Católica do Rio de Janeiro - PUC, e-mail: rwerneck@econ.puc-rio.br.

** O autor agradece o apoio de Marina Figueira de Mello e Fernando Blanco, no esforço de pesquisa que deu lugar a este trabalho, e os comentários de Dionísio Carneiro a uma versão preliminar.
} 


\section{INTRODUÇÃO}

Em setembro de 1997, o governo anunciou que estava preparando uma nova proposta de reforma tributária, que oportunamente seria encaminhada ao Congresso. $\mathrm{Na}$ ocasião, foram apenas delineados os pontos essenciais das modificações pretendidas pela reforma. Desde então a iniciativa vem despertando grande interesse e dando lugar a um intenso debate sobre o detalhamento da reforma e seus possíveis desdobramentos. ${ }^{1}$

A proposta envolve uma transformação substancial da tributação indireta no país, com a eliminação do ISS, do ICMS, do IPI, da COFINS e do PIS-PASEP e sua substituição por três novos impostos: um imposto nacional sobre valor adicionado, com base no consumo, um imposto sobre vendas a varejo, com receita compartilhada entre estados e municípios, e um imposto seletivo, sobre uma base ainda indefinida, mas que possivelmente incluiria fumo, bebidas, combustíveis, veículos, energia elétrica e serviços de telecomunicações. Embora se tenha aventado a possibilidade de que a competência para cobrança do imposto seletivo possa vir a ser distribuída entre a União e os estados, a questão ainda permanece em aberto.

Uma reforma com a abrangência que vem sendo aventada só será viável se for capaz de respeitar simultaneamente um conjunto severo de restrições. De um lado, a precariedade do atual quadro fiscal não deixa espaço para acomodação de qualquer redução significativa, mesmo transitória, da receita tributária agregada. De outro, é pouco provável que o redesenho do federalismo fiscal brasileiro, envolvido na proposta, possa contemplar qualquer solução que venha a impor alterações substanciais na repartição da receita tributária agregada entre União, estados e municípios; ou mesmo soluções que imponham perdas significativas de receita a determinados estados, especialmente àqueles que têm maior peso político e econômico na federação. Um terceiro grupo de restrições advém da necessidade inadiável de fazer da reforma um instrumento eficaz de aumento do grau de eficiência com que opera a economia brasileira e, em particular, da superação das dificuldades que há algum tempo vêm aflorando nas suas contas externas, não obstante o êxito do esforço de estabilização no combate à inflação.

Analisar em que grau as modificações do sistema tributário que vêm sendo aventadas serão capazes de lidar simultaneamente com todas estas restrições, tentar antever possíveis dificuldades e conceber formas de evitá-las ou superá-las é o objetivo maior deste trabalho. Foge ao seu escopo, a consideração de propostas alternativas a que o governo vem aventando. $\mathrm{O}$ trabalho visa tão-somente ajudar a explorar os desdobramentos lógicos da reforma proposta.

Na próxima seção, desenvolve-se um modelo básico de consistência para análise da reforma, que é utilizado na seção 3 para uma bateria inicial de exercícios de

\footnotetext{
${ }^{1}$ Ver, por exemplo, CNI (1998), onde podem ser encontradas as transcrições de depoimentos detalhados do secretário executivo do Ministério da Fazenda e do secretário da Receita Federal sobre a proposta de reforma.
} 
simulação. O modelo é posteriormente aperfeiçoado na seção 4, para acomodar efeitos que não puderam ser adequadamente tratados de início. A seção seguinte analisa uma nova bateria de exercícios de simulação, com base na versão aperfeiçoada do modelo. Finalmente, na seção 6, examinam-se de forma sistemática incertezas envolvidas na reforma e seus desdobramentos.

\section{UM MODELO DE CONSISTÊNCIA}

O ponto de partida do modelo é a restrição de preservação da receita total. Os novos impostos teriam que gerar receita equivalente à que está sendo gerada conjuntamente pelos impostos cuja extinção está sendo considerada. Sendo $R$ esta receita conjunta, definida como

$$
\mathrm{ICMS}+\mathrm{IPI}+\mathrm{ISS}+\mathrm{COFINS}+\mathrm{PIS} / \mathrm{PASEP}=\mathrm{R}
$$

pode-se escrever a restrição de preservação da receita total como

$$
\mathrm{SEL}+\mathrm{IVA}+\mathrm{IVV}=\mathrm{R}
$$

onde SEL, IVA e IVV são, respectivamente, as receitas provenientes do imposto seletivo, do imposto sobre valor adicionado e do imposto sobre vendas a varejo.

Há também um conjunto de restrições que diz respeito à preservação da receita de cada esfera de governo. A receita total $R$, atualmente dividida entre a União, estados e municípios nas parcelas RUA, REA, e RMA, continuaria a ser compartilhada exatamente da mesma forma (a letra $A$ designando atual em cada variável). O que significa escrever

$$
\begin{aligned}
& \mathrm{RU}=\mathrm{RUA} \\
& \mathrm{RE}=\mathrm{REA} \\
& \mathrm{RM}=\mathrm{RMA} \\
& \mathrm{E}, \mathrm{e} \text { claro, } \\
& \mathrm{RU}+\mathrm{RE}+\mathrm{RM}=\mathrm{R}=\mathrm{RUA}+\mathrm{REA}+\mathrm{RMA}
\end{aligned}
$$

Um outro conjunto de restrições relaciona-se à preservação da receita de cada estado. Se atualmente, a parcela $R E A$ que cabe aos estados no total de recursos arrecadados $\mathrm{R}$, pode ser escrita como o somatório de parcelas $R E A_{j}$ que cabem a cada estado

$$
\mathrm{REA}=\sum \mathrm{REA}_{\mathrm{j}}
$$

então, as restrições de preservação de receita de cada estado podem ser reescritas como

$$
\mathrm{RE}_{\mathrm{j}}=\mathrm{REA}_{\mathrm{j}}
$$

para todo $j$. 
A receita do imposto seletivo depende da base potencial do imposto $B_{S E L}$, do grau de aproveitamento desta base, medida pelo coeficiente $a_{5} E L$ e da alíquota média do imposto $T_{S E L}$ Pode-se, portanto, escrever

$$
\mathrm{SEL}=\mathrm{t}_{\mathrm{SEL}} \alpha_{\mathrm{SEL}} \mathrm{B}_{\mathrm{SEL}}
$$

onde, naturalmente,

$$
0<\alpha_{\text {SEL }}<1
$$

Da mesma maneira, a receita do imposto sobre valor adicionado, pode ser escrita como

$$
\mathrm{IVA}=\mathrm{t}_{\mathrm{IVA}} \alpha_{\mathrm{IVA}} \mathrm{B}_{\mathrm{IVA}}
$$

onde $B_{I V A}$ é a base potencial deste imposto, $t_{I V A}$ a alíquota e $\alpha_{I V A}$ o coeficiente de aproveitamento desta base, também medido por um número positivo menor do que 1.

O imposto sobre vendas a varejo seria arrecadado pelos estados e compartilhado com os municípios. A receita bruta deste imposto no estado $j$ seria dada por

$$
\operatorname{IVV}_{\mathrm{j}}=\mathrm{t}_{\mathrm{j}} \alpha_{\mathrm{j}}\left(1+\mathrm{t}_{\mathrm{IVA}}\right) \alpha_{I V A} \mathrm{~B}_{I V A j}
$$

O imposto incidiria sobre o valor do produto ou serviço já acrescido do imposto sobre valor adicionado. Se $B_{1} V A i$ é a base potencial do IVA no estado $j$, a base potencial do imposto sobre vendas a varejo seria a base efetiva do IVA, aIVA $B I V A i$ multiplicada por $\left(1+t_{I V A}\right)$. O grau de aproveitamento desta base no estado $j$ é denotado por $a_{j}$ e a alíquota local de IVV por $t_{j}$.

Assim, a receita total do imposto sobre vendas a varejo arrecadada em todo os estados seria dada por

$$
\operatorname{IVV}=\sum\left[\mathrm{t}_{\mathrm{i}} \alpha_{\mathrm{j}}\left(1+\mathrm{t}_{\mathrm{IVA}}\right) \alpha_{\mathrm{IVA}} \mathrm{B}_{\mathrm{IVAj}}\right]
$$

expressão que pode ser reescrita como

$$
\text { IVV }=\alpha_{\text {IVA }} B_{\text {IVA }} \sum t_{i} \alpha_{j}\left(1+t_{\text {IVA }}\right) B_{\text {IVAj }}
$$

onde

$$
\mathrm{b}_{\text {IVAj }}=\mathrm{B}_{\text {IVA } \mathrm{j}} / \mathrm{B}_{\mathrm{IVA}}
$$

é a participação do estado $j$ na base potencial do IVA e, naturalmente,

$$
\sum \mathrm{b}_{\mathrm{IVA} j}=1
$$

Supondo que tanto o imposto seletivo como o imposto sobre valor adicionado venham a ser integralmente arrecadados pela União, a receita que caberia ao estado $j$ seria dada por

$$
R E_{j}=\left(1-m_{j}\right) I V V_{j}+T R_{j}
$$


onde $m$. é parcela da arrecadação do IVV que o estado $j$ transfere aos seus municípios e $T R_{i}$. o montante de transferências federais recebidas pelo Estado a título de repasse da arrecadação do IVA e do imposto seletivo. Esta equação poderia ser alterada sem maiores dificuldades para acomodar um arranjo alternativo, que também vem sendo considerado na proposta de reforma, de atribuir aos estados competência para explorar parte da base do imposto seletivo. Bastaria incluir no lado direito da equação acima um termo referente à arrecadação deste imposto pelo estado $j$. Contudo, como será arguido abaixo, a divisão ou não da base do imposto seletivo entre a União e os estados não parece fazer parte das questões mais complexas colocadas pela proposta de reforma. O arranjo mais simples assumido na equação [15] não afeta a essência das conclusões que podem ser extraídas do modelo.

O total de transferências federais recebidas pelos estados a título de repasse da arrecadação do IVA e do imposto seletivo seria dado por

$$
\mathrm{TR}=\sum \mathrm{TR}_{\mathrm{j}}
$$

e a receita total proveniente dos três novos impostos que, direta ou indireta mente, caberia aos Estados por

$$
\mathrm{RE}=\sum \mathrm{RE}_{\mathrm{j}}
$$

Analogamente, a receita total proveniente dos três novos impostos que, direta ou indiretamente, caberia aos municípios seria dada por

$$
R M=\sum m_{j} I V V_{j}+T R M
$$

onde a somatória do lado direito da expressão é a parcela total que cabe aos municípios na receita do IVV e TRM é o montante de transferências federais recebidas pelos municípios a título de repasse da arrecadação do IVA e do imposto seletivo.

Descrito o modelo, pode-se agora substituir as equações [7], [9] e [11] na equação [2] e reescrever a restrição de preservação da receita total como

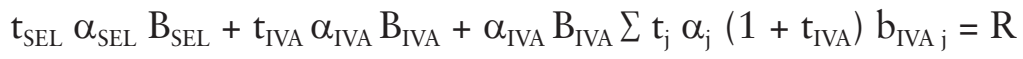

Esta é a equação central do modelo de consistência. Em princípio, há uma infinidade de combinações de valores das variáveis envolvidas que deveria permitir que a arrecadação total dos três impostos iguale à receita requerida $R$. Há que se escolher qual variável deve ser tratada como variável de ajuste. A escolha óbvia parece ser a alíquota do imposto sobre valor adicionado $t_{I V A}$ dado o papel destacado que caberia ao IVA entre os novos impostos indiretos. Resolvendo-se a equação acima para $t_{I V A}$ tem-se

$$
t_{I V A}^{*}=\frac{R-t_{\text {SEL }} \alpha_{\text {SEL }} B_{\text {SEL }}-\alpha_{\text {IVA }} B_{\text {IVA }} \sum t_{j} \alpha_{j} b_{\text {IVA } i}}{\alpha_{\text {IVA }} B_{\text {IVA }}\left(1+\Sigma t_{j} \alpha_{j} b_{\text {IVA }}\right)}
$$

Para cada conjunto de valores atribuídos aos parâmetros e variáveis envolvidos no lado direito da expressão, tem-se a alíquota de imposto sobre valor adicionado $T_{I V A}$ * requerida para gerar a receita total $R$. 
Determinada a alíquota requerida $T_{I V A}$ *, pode-se determinar de que forma terá que ser redistribuída a receita total $R$ para que nenhuma esfera de governo nem nenhum estado tenha perda de receita. A substituição da equação [10] em [15], o uso da equação [13], da restrição estabelecida pela equação [6] e, por fim, a inserção de $T_{I V A}$ * na equação resultante permitem obter

$\mathrm{TR}_{\mathrm{j}}=\mathrm{REA}_{\mathrm{j}}-\left(1-\mathrm{m}_{\mathrm{j}}\right) \mathrm{t}_{\mathrm{j}} \alpha_{\mathrm{j}}\left(1+\mathrm{t}_{\mathrm{IVA}}{ }^{*}\right) \mathrm{b}_{\mathrm{IVA}} \alpha_{\mathrm{IVA}} \mathrm{B}_{\mathrm{IVA}}$

que determina as transferências federais necessárias para atender a restrição de preservação da receita do estado $j$.

A substituição desta expressão na equação [16] permite obter a equação abaixo

$$
\mathrm{TR}=\sum \mathrm{REA}_{\mathrm{j}}-\left(1+\mathrm{t}_{\mathrm{IVA}}{ }^{*}\right) \alpha_{\mathrm{IVA}} \mathrm{B}_{\mathrm{IVA}} \sum\left(1-\mathrm{m}_{\mathrm{j}}\right) \mathrm{t}_{\mathrm{j}} \alpha_{\mathrm{j}} \mathrm{b}_{\mathrm{IVA}}
$$

que determina o total de transferências federais recebidas pelos estados a título de repasse da arrecadação do IVA e do imposto seletivo.

Da mesma maneira, a substituição da equação [10] em [18] e o uso da equação [13] e da restrição estabelecida pela equação [3c] leva a

$$
\mathrm{TRM}=\mathrm{RMA}-\alpha_{\mathrm{IVA}} \mathrm{B}_{\mathrm{IVA}} \sum \mathrm{m}_{\mathrm{j}} \mathrm{t}_{\mathrm{j}} \alpha_{\mathrm{j}}\left(1+\mathrm{t}_{\mathrm{IVA}}{ }^{*}\right) \mathrm{b}_{\mathrm{IVA}}
$$

que determina o total de transferências federais aos municípios requerido para atender a restrição de preservação da receita dos municípios.

\section{SIMULAÇÕES}

A inserção de valores plausíveis para os parâmetros e variáveis exógenas no modelo permite a sua utilização para exercícios de simulação. Com o propósito de simplificar a análise e a comparação dos resultados de tais exercícios, adotou-se uma agregação da esfera estadual em três "estados", definidos segundo os critérios descritos na tabela 3.1. Dada a natureza da proposta, os estados das regiões Norte e Nordeste, já mais dependentes de transferências federais, tenderiam a ser afetados pela reforma de maneira algo peculiar. Nos demais estados da federação, onde a receita própria tende a assumir uma importância relativa maior, o impacto seria distinto. E São Paulo, pela sua dimensão e particularidade, justifica um tratamento em separado.

Tabela 3.1 Agregação da Esfera Estadual

\begin{tabular}{ll}
\hline “Estados" & \multicolumn{1}{c}{ Definição } \\
\hline Estado1 & Estados das regiões Norte e Nordeste \\
Estado2 & Estados das regiões Sudeste (excl. São Paulo), Sul e Centro-Oeste \\
Estado3 & SãoPaulo \\
\hline
\end{tabular}


Já há dados disponíveis, referentes ao ano de 1997, para se estimar o valor de $R$, definida na equação [1] como a receita total gerada pelos impostos cuja extinção vêm sendo considerada. A única exceção é a receita do ISS em 1997 que, na tabela 3.2 abaixo, foi estimada a partir da receita de 1996 e da suposição de que a expansão da mesma acompanhou a taxa de crescimento do PIB nominal em 1997. Como mostra a tabela, a massa de recursos cuja arrecadação seria alterada pela reforma atingiu em 1997 um total de R \$ 107,9 bilhões.

A coluna à esquerda da tabela 3.2 decompõe a receita total entre União, estados e municípios e respectivos impostos. Naturalmente, a distribuição final desta receita, deve levar em conta o que dela é transferida pela União aos estados e por estes aos municípios. Estimados os valores destas transferências, nas colunas intermediárias da tabela, apresenta-se na última coluna à direita, a decomposição da receita total, da forma como é efetivamente compartilhada entre as várias esferas de governo e dentro da esfera estadual. É daqui que podem ser extraídos os valores para as variáveis $R U A, R E A, R M A$ e $R E A_{j}$ envolvidas nas equações [3] e [6]. Dos $\mathrm{R} \$ 107,9$ bilhões arrecadados pelos impostos mencionados em 1997, R \$35,8 bilhões terminaram destinados à esfera federal, $\mathrm{R} \$ 48,8$ à estadual e $\mathrm{R} \$ 23,3$ bilhões à municipal.

Tabela 3.2

Estimativa da Receita Total dos Impostos que Seriam Extintos e de sua Partilha Atual 1997 (em bilhões de reais)

\begin{tabular}{|c|c|c|c|c|}
\hline & Arrecadação & $\begin{array}{c}\text { Transferência da } \\
\text { União a Estados } \\
\text { e Minicípios }\end{array}$ & $\begin{array}{c}\text { Transferências } \\
\text { Estaduais aos } \\
\text { Minicípios }\end{array}$ & $\begin{array}{c}\text { Distribuição } \\
\text { Final da } \\
\text { Receita }\end{array}$ \\
\hline União & 43.5 & -7.7 & & 35.8 \\
\hline $\mid \mathrm{PI}$ & 16.8 & & & \\
\hline COFINS & 19.1 & & & \\
\hline PIS/PASEP & 7,6 & & & \\
\hline Estados & 59.6 & 4.1 & -14.9 & 48.8 \\
\hline ICMS & 59.6 & & & \\
\hline Norte-Nordeste & 10.5 & 3.2 & -2.6 & 11.1 \\
\hline $\begin{array}{l}\text { Sul-Sudeste } \\
\text { (excl.SP) - C.Oeste }\end{array}$ & 25.5 & 0.7 & -6.4 & 19.9 \\
\hline São Paulo & 23.5 & 0.2 & -5.9 & 17.8 \\
\hline Municípios & 4.8 & 3.6 & 14.9 & 23.3 \\
\hline ISS* & 4.8 & & & \\
\hline TOTAL & 107.9 & & & 107.9 \\
\hline
\end{tabular}

Dado estimado

O valor da variável $b_{I V A}$ que mede a base potencial do IVA, merece algumas considerações. Não estão ainda disponíveis os dados de contas nacionais para 1997. De acordo com as contas de 1996, o consumo agregado das famílias teria alcança- 
do R \$ 484,2 bilhões, a preços daquele ano. Supondo que a evolução deste agregado tenha acompanhado a taxa de expansão do PIB nominal, chega-se a uma cifra de consumo nominal para 1997 da ordem de R \$ 520 bilhões. É verdade que este valor supostamente já incorpora impostos indiretos sobre consumo. E o modelo pressupõe uma alíquota "por fora" do IVA. Por outro lado, sabe-se que as contas nacionais possivelmente subestimam o PIB em um montante ponderável, ainda que desconhecido. E que a maneira residual pela qual se estima o consumo nas contas acaba concentrando sobre este agregado boa parte da subestimativa do PIB. Tendo tudo isto em conta, decidiu-se trabalhar com um valor para $B_{I V A}$, a base potencial do IVA, de R \$ 500 bilhões. Naturalmente, a base efetiva tenderá a ser significativamente menor, dependendo do grau de aproveitamento da base, determinado pelo coeficiente $\alpha_{I V A}{ }^{\prime}$ cujo valor ainda deverá ser objeto de extensa discussão.

As hipóteses sobre os valores dos parâmetros e variáveis exógenas envolvidas na determinação da arrecadação e partilha do IVV estão relacionadas na tabela 3.3 abaixo.

Tabela 3.3

Parâmetros e Variáveis Exógenas Envolvidas na Determinaçâo da Receitado IVV

\begin{tabular}{l|c|c|c|c}
\hline \multirow{2}{*}{ "Estado" } & \multicolumn{4}{|c}{ Parâmetros e Variáveis Exógenas } \\
\cline { 2 - 5 } & $\mathrm{b}_{\mathrm{IVAj}}$ & $\alpha_{\mathrm{j}}$ & $\mathrm{t}_{\mathrm{j}}$ & $\mathrm{m}_{\mathrm{j}}$ \\
\hline Estado 1: Norte-Nordeste & 0,20 & 0,4 & 0,05 & 0,3 \\
\hline Estado 2: Sudeste (excl. SP)+Sul+Centro-Oeste & 0,45 & 0,6 & 0,06 & 0,3 \\
\hline Estado 3: SâoPaulo & 0,35 & 0,7 & 0,06 & 0,3 \\
\hline
\end{tabular}

A coluna referente a $b_{I V A j}$ apresenta os coeficientes de distribuição, entre os estados, da base potencial do IVA, o que na verdade envolve a distribuição regional do consumo. A hipótese adotada é a de que $20 \%$ da base esteja contida nos estados da região Norte-Nordeste, $35 \%$ em São Paulo e $45 \%$ no restante do país. Os parâmetros $\alpha_{j}$ como já se viu na discussão da equação [10], aferem o estreitamento adicional que sofre a base do IVV, além do advindo do coeficiente $\alpha_{I V A}$ em decorrência das dificuldades de coleta de um tributo que se arrecada de forma muito pulverizada, entre um número relativamente grande de estabelecimentos de varejo. ${ }^{2}$ Presumiu-se que este coeficiente seja de 0,7 em São Paulo, 0,4 no Norte-Nordeste e 0,6 no restante do país. No que diz respeito às alíquotas estaduais do IVV, adotou-se a hipótese de que seriam de $6 \%$ em todo o País, com exceção dos estados do Norte e do Nordeste, onde seriam de $5 \%$. Restam os parâmetros $m_{\mathrm{j}}$ de partilha da receita estadual do IVV com os

\footnotetext{
2 Autoridades fazendárias de São Paulo têm manifestado a sua apreensão com as possíveis dificuldades de ter que fiscalizar adequadamente o que é estimado entre 300 e 400 mil estabelecimentos varejistas existentes no território paulista. Ver, por exemplo, declarações do secretário de Fazenda de São Paulo, registradas em CNI (1998).
} 
municípios. Presumiu-se que, em todos os estados, caibam aos municípios uma participação de $30 \%$ na arrecadação do IVV.

Que hipóteses podem ser feitas sobre os parâmetros e variáveis que deverão governar a arrecadação do imposto seletivo? As próprias autoridades responsáveis pela proposta de reforma tributária vêm sendo intencionalmente vagas sobre a definição da base e da estrutura de alíquotas deste imposto que, segundo elas, deveriam ser tratadas como variáveis de ajuste na reforma. Como mostra a tabela 3.2 acima, o IPI gerou em 1997 um pouco menos de R \$ 17 bilhões de receita. A base do novo imposto seletivo deverá incluir uma parte importante da base do IPI fumo, bebida e automóveis - e ainda uma parte ponderável da atual base do ICMS - como serviços de eletricidade e telecomunicações - de onde os Estados têm extraído farta receita. Contudo, é bom lembrar que tais serviços deverão também entrar na base do IVA e, portanto, a fixação das alíquotas do imposto seletivo que sobre ele incidirem terá que levar isto em conta. Dificilmente tais alíquotas poderão ser tão altas quanto as atuais alíquotas do ICMS sobre estes serviços. Por ora, para os exercícios de simulação iniciais, será adotada a hipótese de que o imposto seletivo seja capaz de gerar $\mathrm{R} \$ 20$ bilhões de receita anual, ou seja, que a expressão $S E L=t_{S E L} \alpha_{S E L} B_{S E L}$ no modelo atinja este valor. Contudo, a sensibilidade de alguns dos resultados a esta premissa deverá ser devidamente explorada. E, mais adiante, em outro conjunto de exercícios, a arrecadação do imposto seletivo será tratada, de maneira alternativa, como variável endógena.

De posse do conjunto de hipóteses discutido acima, os exercícios de simulação podem ser iniciados a partir da equação [20]. O gráfico da figura 3.1 abaixo, gerado por esta equação, mostra os níveis da alíquota requerida do IVA para diferentes grau de estreitamento da base $\left(\alpha_{I V A}\right)$ e distintos valores da receita do imposto seletivo (SEL).

A curva na posição intermediária, referente à hipótese de que SEL seja igual $\mathrm{R} \$ 20$ bilhões, indica que a alíquota requerida pode chegar a ser tão baixa quanto $15,5 \%$ para um imposto de base muito ampla, com ${ }^{\mathrm{i}} \mathrm{ivA}=0,9$, mas pode também chegar a níveis proibitivos, em torno de $40 \%$, para um imposto de base estreita e $\alpha_{I V A}=0,4 .{ }^{3}$ Se a receita do imposto seletivo vier a atingir $\mathrm{R} \$ 25$ bilhões, em vez de $\mathrm{R} \$ 20$ bilhões, a alíquota requerida baixaria $15,5 \%$ para $14,4 \%$ quando $\alpha_{\mathrm{IVA}}=0,9$. Para valores de aivA entre 0,75 e 0,80 , cada bilhão adicional de receita do imposto seletivo propiciaria uma redução de cerca de um quarto de ponto percentual na alíquota requerida do IVA.

$\mathrm{Na}$ figura 3.2, fixa-se novamente o valor da receita do imposto seletivo SEL em R \$ 20 bilhões e verifica-se qual é a sensibilidade da alíquota requerida do IVA às alíquotas do IVV. A curva mais baixa refere-se ao caso em que as alíquotas $t_{i}$ do IVV foram mantidas nos níveis apresentados na tabela 3.3 acima.

\footnotetext{
${ }^{3}$ Note-se que, como o modelo pressupõe uma alíquota "por fora", a alíquota de 15,5\% corresponderia a uma "por dentro" de aproximadamente $13,4 \%$.
} 
Figura 3.1

Alíquota Requerida do IVA para Diferentes Valores de $\alpha_{I V A}$ e de SEL

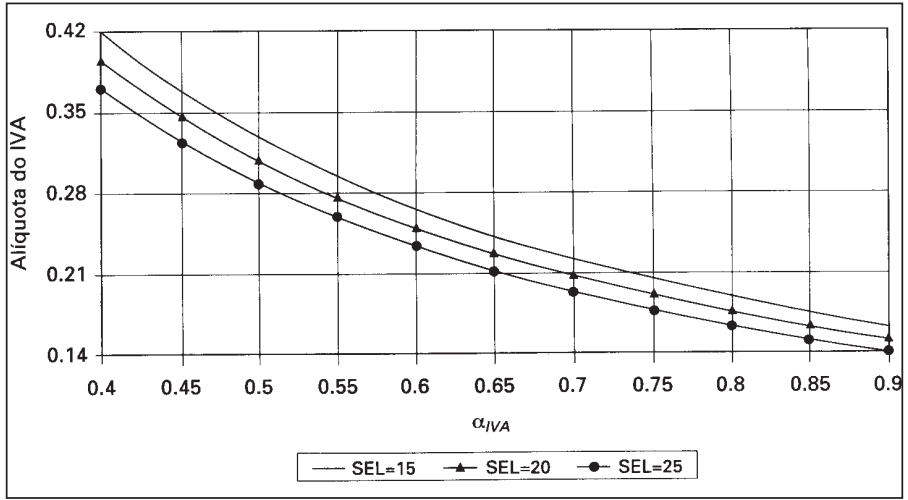

Figura 3.2

Alíquota Requerida do IVA para Diferentes Valores de $\alpha_{I V A}$ e de $t_{j}$

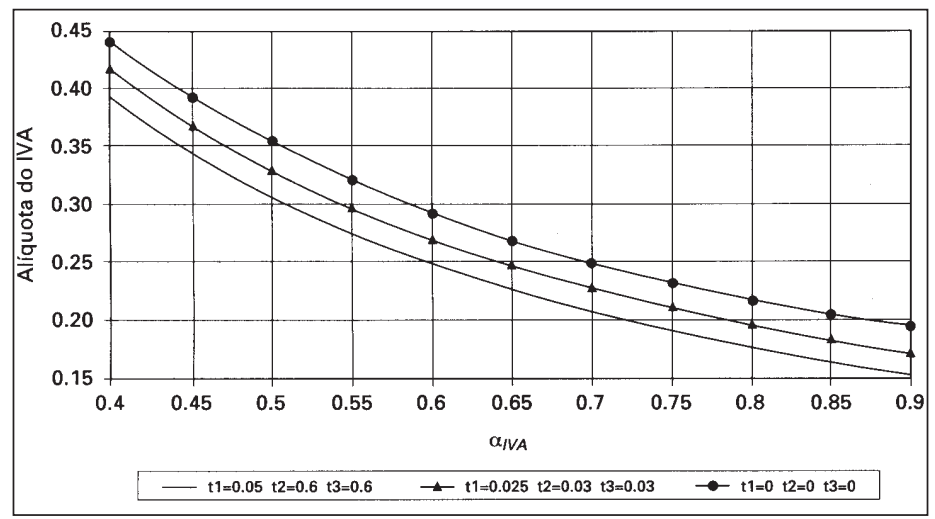

A curva em posição intermediária corresponde ao caso em que estes níveis foram cortados pela metade. Já na curva mais alta, os $t_{j}$ foram simplesmente reduzidos a zero, o que simula os efeitos da eliminação pura e simples do IVV. Para valores de $\alpha_{I V A}$ entre 0,75 e 0,8 , a eliminação do IVV implicaria uma elevação de 4,1 a 4,2 pontos percentuais na alíquota requerida do IVA. Um custo que os críticos mais ardentes do IVV, preocupados com as possíveis dificuldades envolvidas na sua arrecadação, provavelmente considerariam mais do que aceitável. Por que a eliminação de alíquotas de 5 a $6 \%$ de IVV exigiria apenas uma elevação de pouco mais de 4 pontos percentuais na alíquota do IVA, para preservação da receita total? A razão é o estreitamento adicional da base efetiva do IVA a que está submetida a base do IVV, exatamente em decorrência dessas dificuldades, conforme suposto na equação [10] acima e nos valores dos parâmetros $\alpha_{j}$ na tabela 3.3.

Restabelecidas as hipóteses para alíquotas do IVV apresentadas de início na tabela 3.3, e mantida a receita SEL do imposto seletivo em $\mathrm{R} \$ 20$ bilhões, pode-se 
obter, através das equações [21] a [23], as receitas do IVA e do IVV e os fluxos requeridos de transferências. A evolução destas variáveis, para diferentes valores de $\alpha_{I V A}$, pode ser examinada na bateria de gráficos apresentada na figura 3.3. Como mostra o gráfico 1 da figura, a arrecadação do IVA teria que ser tanto maior quanto menor fosse o valor de aiv A. O estreitamento da base do IVA provoca um encolhimento da base e da arrecadação do IVV, como se vê no gráfico 2, o que aumenta o requisito de receita do IVA. A receita requerida do IVA variaria entre aproximadamente 70 e 78 bilhões, o que deve ser comparado com a receita total de ICMS de pouco menos de R \$ 60 bilhões arrecadada em 1997 pelos estados.

Os gráficos 3 e 4 mostram para diferentes valores de $\alpha_{I V A}$ as transferências federais aos estados e municípios que seriam requeridas. Quanto menor o valor de $\alpha_{I V A}$ e, portanto, menor a arrecadação do IVV, maior a dependência das esferas infranacionais de governo às transferências federais. A relações entre $\alpha_{I V A}$, o total destas transferências e este total medido como proporção da arrecadação do IVA podem ser analisadas nos gráficos 5 e 6 . As transferências totais variariam entre cerca de R\$ 54 bilhões e pouco mais R $\$ 62$ bilhões, o que representaria entre 77 e $80 \%$ da receita do IVA. A desagregação da receita do IVV e das transferências federais entre os “estados" pode ser examinada nos gráficos 7 e 8 . Com $\alpha_{I V A}$ igual a 0,9, por exemplo, a receita bruta do IVV em São Paulo atingiria cerca de R \$ 7,6 bilhões. De acordo com as hipóteses sobre $m_{j}$ feitas na tabela 3.3, aos municípios caberiam 30\% desta receita, o que deixaria ao estado uma receita líquida própria de $\mathrm{R} \$ 5,3$ bilhões, que implicaria a necessidade de transferências federais de cerca de $\mathrm{R} \$ 12,5$ bilhões para que fosse preservado o mesmo nível de $\mathrm{R} \$ 17,8$ bilhões de recursos a que o estado teve acesso em 1997, conforme visto na tabela 3.2 acima. Naturalmente, à medida que cai o grau de aproveitamento da base do IVA, diminui a receita IVV e aumentam as transferência necessárias à preservação da receita de cada estado.

Antes de dar por encerrada esta bateria de exercícios de simulação, feitos com base no modelo desenvolvido na seção 2 , vale a pena reexaminar a restrição de preservação da receita total, dada pela equação [19] que, com base em [7], pode ser reescrita como

$$
\begin{aligned}
& \text { SEL }+t_{\text {IVA }} \alpha_{I V A} B_{I V A}+\alpha_{I V A} B_{I V A} \sum t_{j} \alpha_{j}\left(1+t_{I V A}\right) B_{I V A j}=R \\
& \text { ou, ainda, como } \\
& \text { SEL = R - }\left(t_{I V A}+\left(1+t_{I V A}\right) \sum t_{j} \alpha_{j} b_{I V A j}\right) \alpha_{I V A} B_{I V A}
\end{aligned}
$$

Esta equação permite, tal como aventado acima, exercícios de simulação em que se determinam, para distintas hipóteses acerca da alíquota $t_{I V A}$ e diferentes valores de $\alpha_{I V A}$, os valores da receita requerida do imposto seletivo $S E L$. Resultados de tais exercícios, para quatro valores de $t_{I V A}$, entre 14 e $20 \%$, podem ser analisados na figura 3.4. No caso mais extremo de estreitamento da base do IVA, a receita requerida do imposto seletivo poderia ser superior a $\mathrm{R} \$ 60$ bilhões, mesmo que se recorresse a uma alíquota de $20 \%$ para o IVA. Para níveis de $\alpha_{I V A}$ da ordem de 0,7 , a receita requerida do imposto seletivo variaria entre $\mathrm{R} \$ 23$ e 45 bilhões, como 
mostra o gráfico, dependendo da alíquota do IVA. E cada ponto percentual de redução desta alíquota exigiria cerca de $\mathrm{R}$ \$ 3,6 bilhões de receita adicional do imposto seletivo para preservar o valor da receita total.

Figura 3.3: Receitas do IVA e do IVV e Transferências Federais aos Estados e Municípios para diferentes valores de $\alpha_{I V A}$ e $S E L=R \$ 20$ bilhões
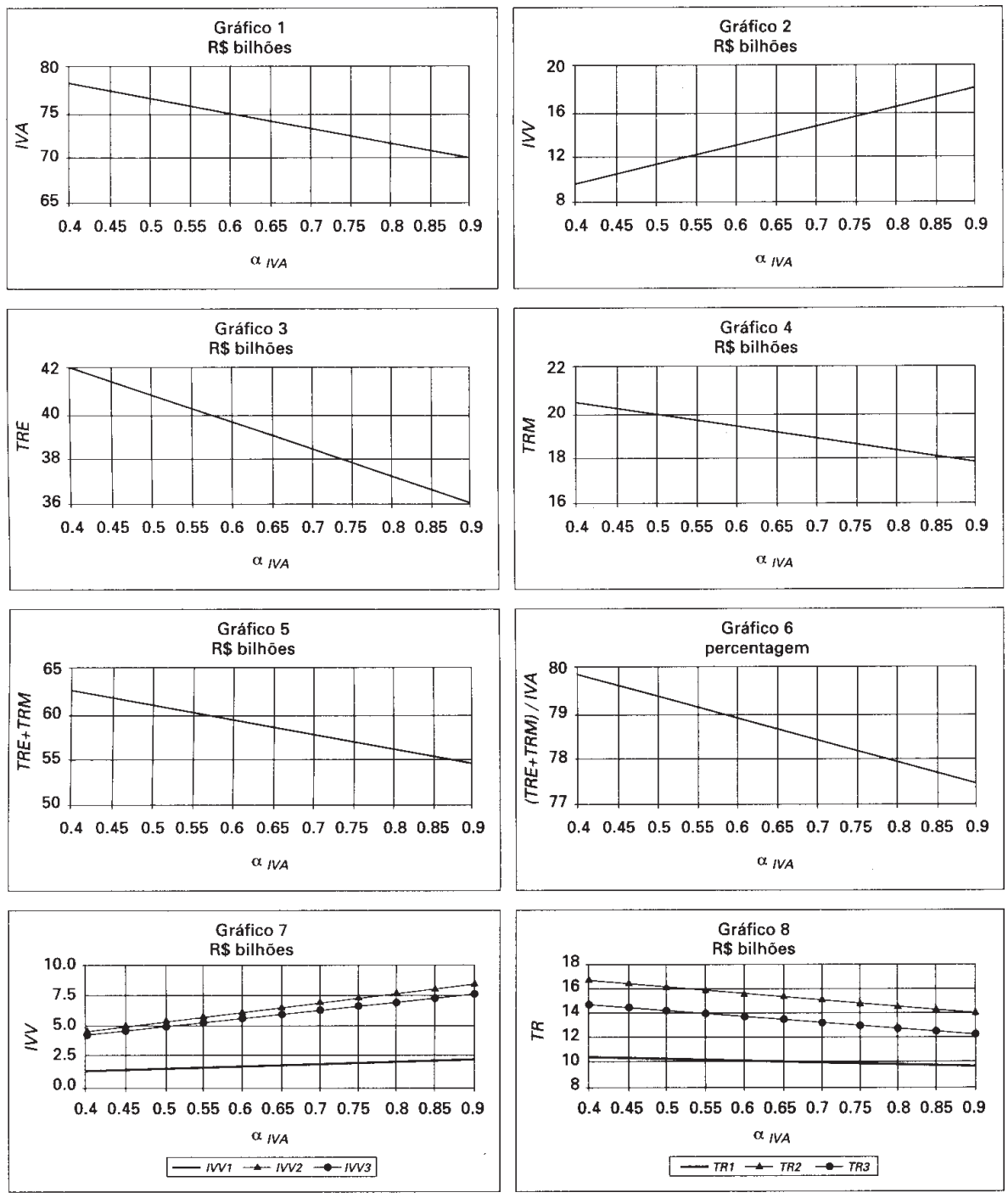
Figura 3.4: Receita Requerida do Imposto Seletivo para Diferentes Valores de $\alpha_{I V A}$ e de $t_{\text {IVA }}$

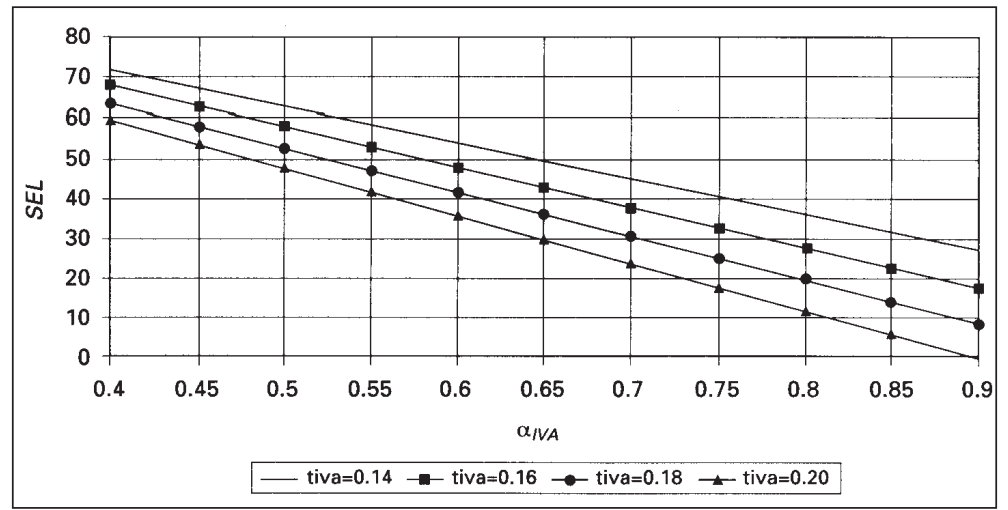

\section{EXTENSÕES DO MODELO BÁSICO}

No modelo de consistência apresentado na seção 2, o grau de aproveitamento efetivo da base do IVA é tratado como uma variável exógena $\alpha_{I V A}$ independente da alíquota do imposto. Contudo, pode ser mais razoável supor que, para uma mesma definição de abrangência da base e um mesmo padrão de eficiência da fiscalização, o grau de aproveitamento efetivo da base deste imposto deva depender da alíquota que se tenta impor. Quanto mais elevada a alíquota, maior o incentivo à evasão e menor o aproveitamento da base.

Uma extensão natural do modelo é, portanto, introduzir a hipótese mais realista de que o grau de aproveitamento efetivo da base do IVA é determinado por

$$
\mathrm{h}=\mathrm{h}\left(\alpha_{I V A}, \mathrm{t}_{I V A}, \mathrm{v}\right)
$$

que simplesmente corrige o valor de $\alpha_{I V A}$, levando em conta a alíquota $t_{I V A}$ através de uma função com elasticidade constante $v$.

Nos exercícios de simulação cujos resultados foram apresentados na figura 3.1, viu-se que, se a receita do imposto seletivo fosse de $\mathrm{R} \$ 20$ bilhões e $\alpha_{I V A}$ fosse igual a 0,9 , o nível requerido de $t_{I V A}$ seria de $15,5 \%$. Pressupunha-se implicitamente no modelo anterior que se este grau de aproveitamento da base do IVA fosse viável quando a alíquota fosse de $15,5 \%$, permaneceria viável quando a alíquota fosse, por exemplo, o dobro, o que é claramente pouco realista. Como se vê no gráfico da figura 4.1 abaixo, em vez de se supor que o grau de aproveitamento efetivo da base do IVA permanece imutável quando a alíquota do imposto aumenta, presume-se agora que caia e tanto mais quanto maior for a elasticidade $v$. Só não cairá se $v=0$, como implicitamente foi suposto no modelo anterior. 
Figura 4.1: Grau de aproveitamento Efetivo da base do IVA quando $\alpha_{I V A}=0.9 \mathrm{~h}\left(\alpha_{I V A}, \mathrm{t}_{\text {IVA }}, \mathrm{v}\right)$

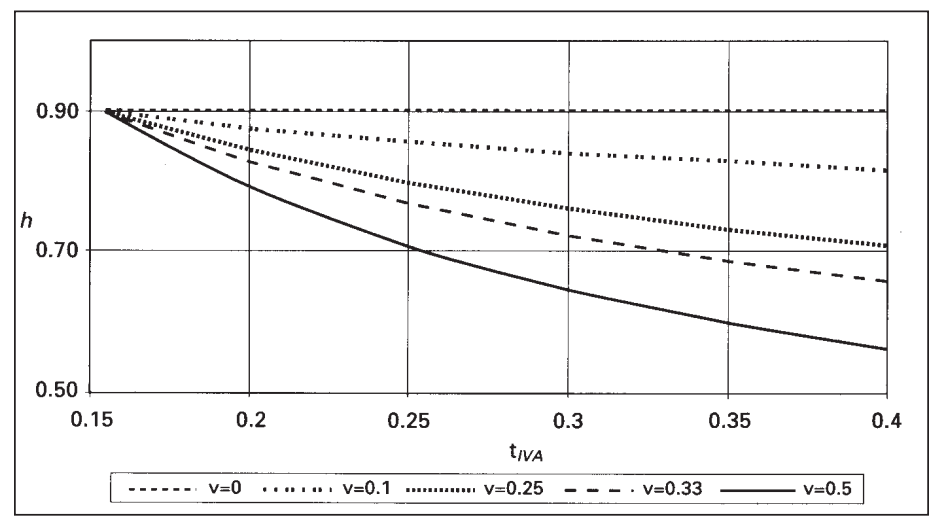

A introdução desta modificação no modelo leva a que a receita do imposto sobre valor adicionado, que era determinada pela equação [9],

$$
\mathrm{IVA}=\mathrm{t}_{\mathrm{IVA}} \alpha_{\mathrm{IVA}} \mathrm{B}_{\mathrm{IVA}}
$$

passe a ser determinada por

$$
\mathrm{IVA}=\mathrm{t}_{\text {IVA }} \mathrm{h}\left(\alpha_{\text {IVA }}, \mathrm{t}_{\mathrm{IVA}}, \mathrm{v}\right) \mathrm{B}_{\text {IVA }}
$$

Leva também a que estrição de preservação da receita total, expressa na equação [19] como

$$
t_{\text {SEL }} \alpha_{\text {SEL }} B_{\text {SEL }}+t_{\text {IVA }} \alpha_{\text {IVA }} B_{\text {IVA }}+\alpha_{\text {IVA }} B_{\text {IVA }} \sum t_{j} \alpha_{j}\left(1+t_{\text {IVA }}\right) b_{\text {IVA } j}=R
$$

seja reescrita como

$$
t_{\text {SEL }} \alpha_{\text {SEL }} B_{\text {SEL }}+t_{\text {IVA }} h\left(\alpha_{\text {IVA }} t_{I V A} v\right) B_{\text {IVA }}+h\left(\alpha_{\text {IVA }} t_{\text {IVA }} v\right) B_{I V A} \sum t_{j} \alpha_{j}\left(1+t_{\text {IVA }}\right) b_{\text {IVA } j}=R
$$

Dados os valores das demais variáveis e parâmetros envolvidos na equação acima, pode-se estabelecer a alíquota do IVA que preserva a receita total, extraindose $t_{I V A}$ * como raiz da equação.

Uma vez estabelecida a alíquota requerida $t_{I V A}$ *, pode-se determinar, tal como no modelo básico, de que forma terá que ser redistribuída a receita total $R$ para que nenhuma esfera de governo nem nenhum estado tenham perda de receita. Novamente, devem ser utilizadas as equações [21] a [23], modificadas apenas pela substituição, em cada uma delas, de aivA por $h\left(\alpha_{I V A} t_{I V A} * v\right)$, que é o grau de aproveitamento efetivo da base do IVA quando $t_{I V A}=t_{I V A}{ }^{*}$, a raiz da equação [27] acima.

\section{NOVAS SIMULAÇÕES}

Atribuindo-se distintos valores à elasticidade $v$, e obtendo-se para cada um deles a raiz $t_{I V A}$ * da equação [27] — para diferentes valores assumidos por $\alpha_{I V A}-$ 
podese traçar a família de curvas apresentadas no gráfico da figura 5.1. Em todas elas, presume se que a receita do imposto seletivo $t_{S E L} a_{S E L} B_{S E L}$ corresponda a R $\$$ 20 bilhões. A curva mais baixa do gráfico, nada mais é do que a mesma curva que ocupava uma posição intermediária no gráfico da figura 3.1 do início da seção 3 . De fato, quando $v=0$, a equação [27] transforma-se novamente na equação [19] e reverte-se ao modelo anterior.

Figura 5.1: Alíquota $t_{/ V A}{ }^{*}$ para diferentes valores de $\alpha_{I V A}$ e de $v$

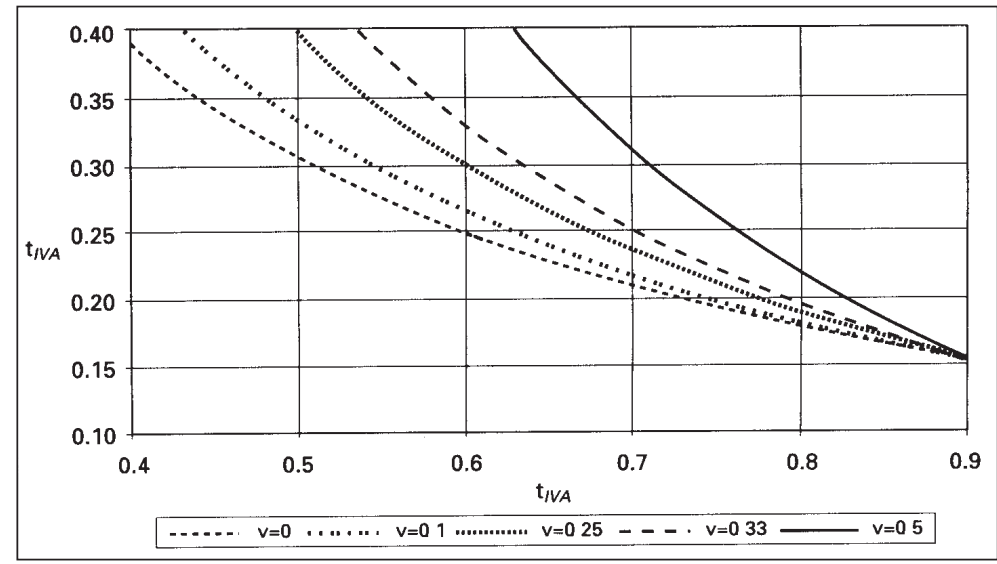

No entanto, quando se atribuem a $v$ valores positivos, os resultados das simulações com o novo modelo tornam-se bem diferentes dos gerados anteriormente. Para cada ' $i v A$ ' a alíquota requerida do IVA parece agora bem maior do que parecia ser no modelo anterior, que não levava em conta o estreitamento da base provocado pela própria elevação da alíquota. Quando se toma $\alpha_{I V A}$ igual a 0,7 , por exemplo, verifica-se que a alíquota requerida que parecia ser de pouco menos de $21 \%$ no modelo anterior, pode passar agora a $25 \%$ se a elasticidade $v$ for igual a 0,33 , ou até superar $30 \%$ se $v$ for igual a 0,5 . O que o gráfico mostra, portanto, é que o trade-off entre $\alpha_{I V A}$ e a alíquota requerida do IVA torna-se agora mais adverso, mesmo quando se supõe valores relativamente baixos para $v$.

Explorando os resultados das simulações de outra forma, a figura 5.2 apresenta curvas de nível para a alíquota requerida $t_{I V A}{ }^{*}$. A linha mais à direita do gráfico, por exemplo, representa o conjunto de todas as combinações de valores deve $\alpha_{I V A}$ que mantém $t_{I V A}{ }^{*}$ igual a $16,6 \%$. Ao longo desta linha, à medida que se aumenta o valor de $v$, o nível de $t_{I V A}$ " pode ser preservado com um aumento relativamente pequeno de aIVA' Mais a esquerda do gráfico, contudo, uma elevação do valor de $v$ tende a exigir uma modificação mais substancial em $\alpha_{I V A}$ para que se mantenha constante o nível de $t_{I V A}{ }^{*}$. 
Figura 5.2: Alí quota Requerida $\mathrm{t}_{\text {IVA }}{ }^{*}$ Curvas de Nível para Diferentes Valores de $v$ e $\alpha_{I V A}$

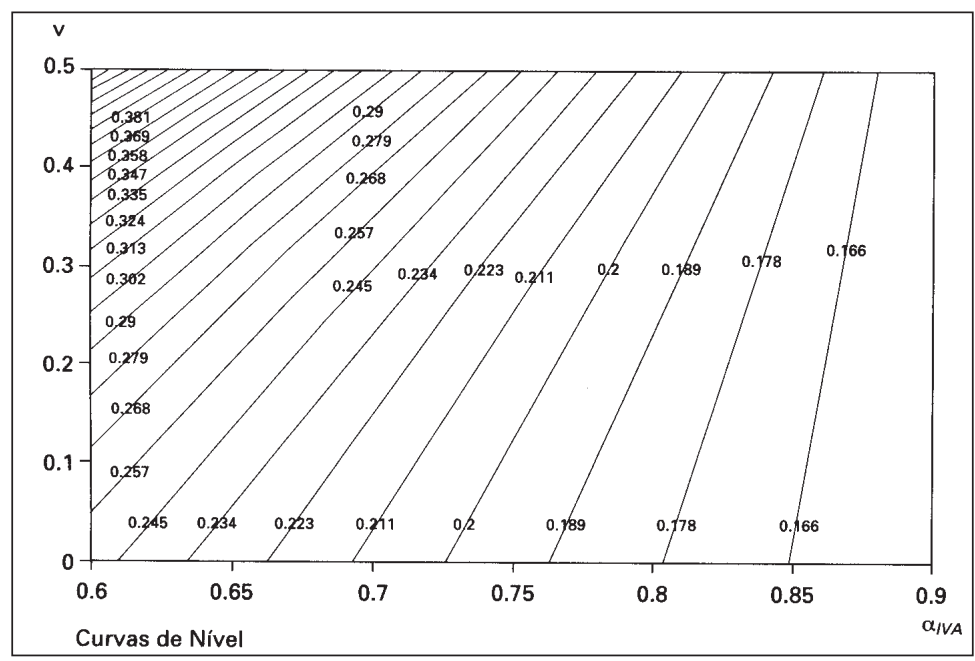

Quanto mais altos os valores de $v$ e mais baixos os de $\alpha_{I V A}$ mais elevados os de $t_{I V A}{ }^{*}$. Na parte superior esquerda do gráfico os níveis requeridos de $t_{I V A}{ }^{*}$ tornamse proibitivos. É exatamente por esta razão que, no gráfico, fixou-se um limite inferior para $\alpha_{I V A}$ igual a 0,6 .

Dando continuidade à análise dos resultados das simulações feitas com base no modelo desenvolvido na seção 4, a figura 5.3 apresenta as receitas do IVA e do IVV, bem como as transferências federais agregadas aos estados e municípios, para diferentes valores deve de $\alpha_{I V A}$ e SEL = R \$ 20 bilhões. Já a desagregação das receitas do IVV e das transferências federais requeridas, por "estado", para diferentes valores deve de $v$ e de a,vA' pode ser examinada no conjunto de gráficos da figura 5.4. Todas as curvas correspondentes a $v=0$, tanto na figura 5.3 como na 5.4, nada mais são do que as já analisadas da seção 3, o que facilita a comparação com os resultados obtidos com base no modelo anterior.

\section{DESDOBRAMENTOS DAS INCERTEZAS ENVOLVIDAS}

O lançamento de uma reforma com a abrangência da que vem sendo proposta envolve incertezas que devem ser devidamente consideradas. O ponto de partida para a análise dos desdobramentos de tais incertezas é a restrição de preservação da receita total, expressa, no modelo básico, através da equação [19],

$$
\mathrm{t}_{\mathrm{SEL}} \alpha_{\mathrm{SEL}} \mathrm{B}_{\mathrm{SEL}}+\mathrm{t}_{\mathrm{IVA}} \alpha_{\mathrm{IVA}} \mathrm{B}_{\mathrm{IVA}}+\alpha_{\mathrm{IVA}} \mathrm{B}_{\mathrm{IVA}} \sum \mathrm{t}_{\mathrm{j}} \alpha_{\mathrm{i}}\left(1+\mathrm{t}_{\mathrm{IVA}}\right) \mathrm{b}_{\mathrm{IVAj}}=\mathrm{R}
$$

posteriormente transformada na equação [27], no modelo desenvolvido na seção 4 .

$$
t_{\text {SEL }} \alpha_{\text {SEL }} B_{\text {SEL }}+t_{\text {IVA }} h\left(\alpha_{\text {IVA, }} t_{I V A}, v\right) B_{\text {IVA }} \sum t_{j} \alpha_{i}\left(1+t_{I V A}\right) b_{I V A j}=R
$$


Figura 5.3: Receitas do IVA e do IVV e Transferências Federais aos Estados e Municípios para diferentes valores de $\alpha_{I V A}$ e SEL $=R \$ 20$ bilhões
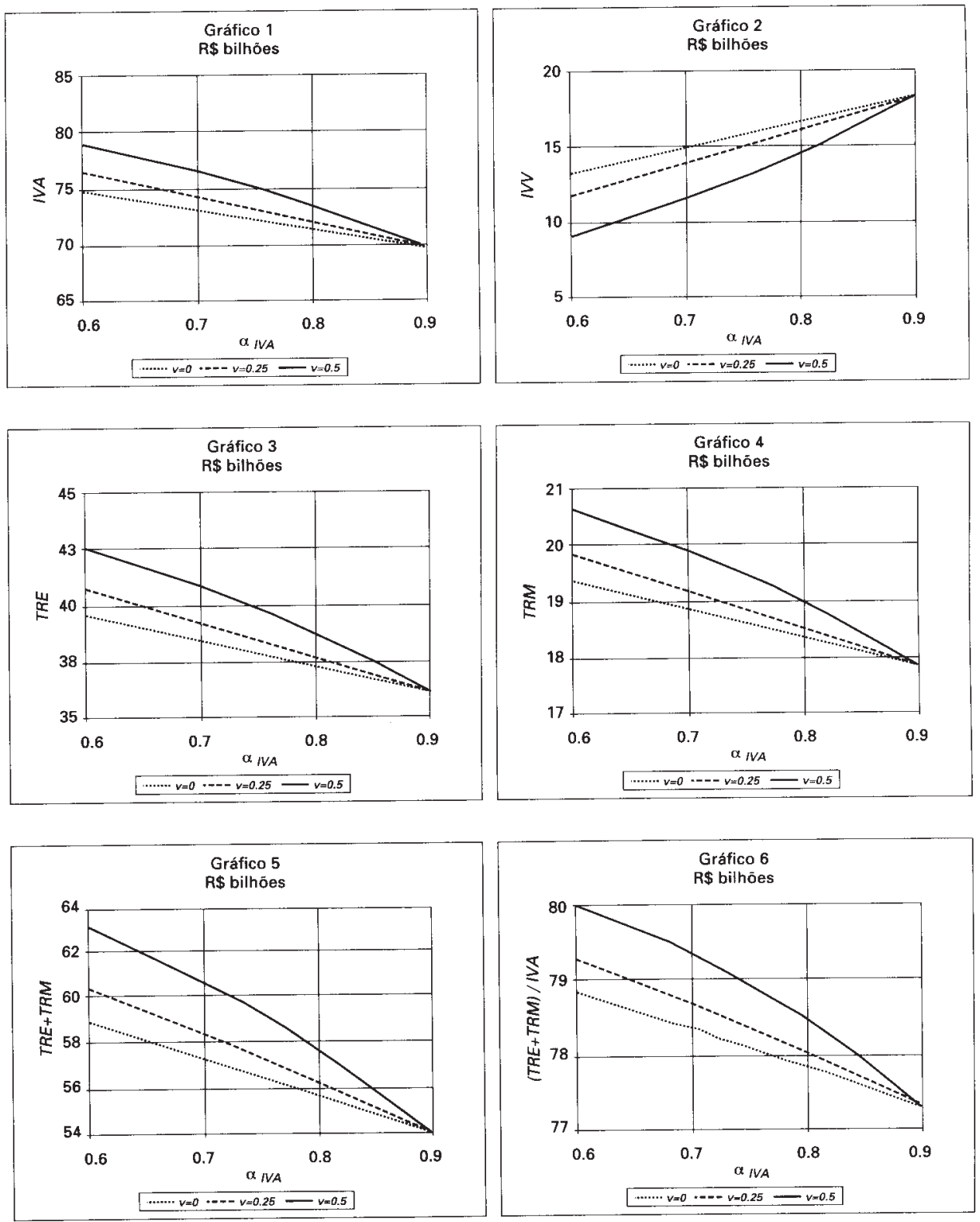
Figura 5.4: Receitas do IVA e do IVV e Transferências Federais por Estado para diferentes valores de $\alpha_{I V A}$ e $S E L=R \$ 20$ bilhões
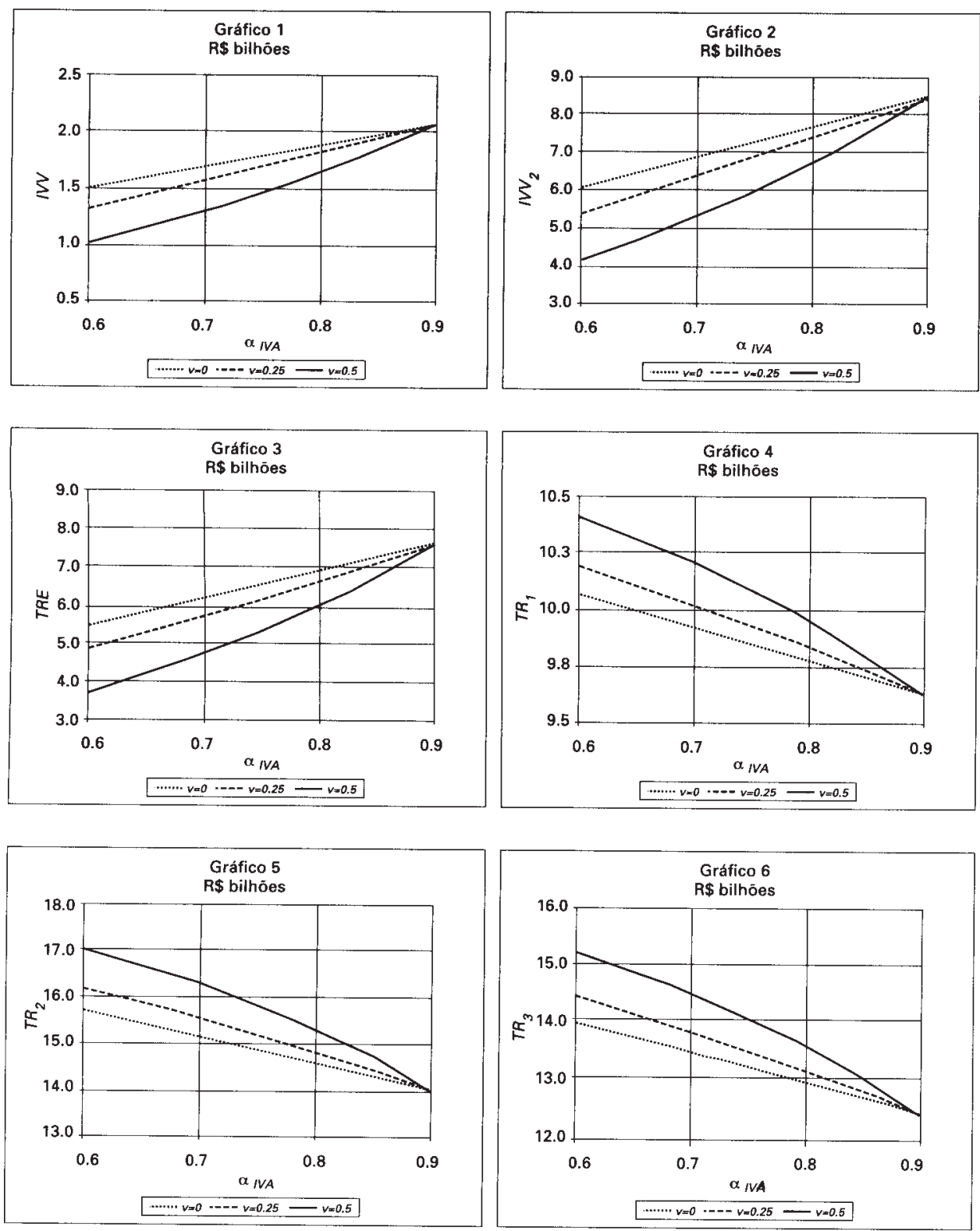
Em ambas, há parâmetros e variáveis exógenas cujos valores ou são conhecidos com razoável certeza ou podem ser estritamente determinados pelo governo. Mas há também variáveis cujos valores envolvem um alto grau de incerteza. A idéia básica desta seção é investigar de que maneira a incerteza sobre tais variáveis se desdobra em incerteza sobre o valor requerido da variável de ajuste nas equações [19] ou [27]. Particularmente incertos, parecem ser os valores de $\alpha_{I V A}$ e ai que devem determinar o grau de aproveitamento das bases potenciais de dois dos novos impostos que seriam introduzidos pela reforma. Para cada um desses impostos, o grau de aproveitamento deverá depender, entre outros fatores, da abrangência da definição legal da base afinal aprovada pelo Legislativo, da extensão das isenções e alíquotas especiais que tiverem que ser concedidas e, é claro, do padrão de eficiência da fiscalização na cobrança do novo imposto.

A análise dos desdobramentos de incertezas deste tipo poderia ser feita através da simulação de um pequeno número de cenários - por exemplo, um médio, um otimista um pessimista - e de alguns poucos exercícios complementares de análise de sensibilidade, que realçassem a importância relativa de variáveis e parâmetros envolvidos no processo. Embora insights interessantes sobre os desdobramentos da reforma pudessem certamente ser obtidos a partir de exercícios de previsão deste tipo, há metodologias mais avançadas que parecem bem mais adequadas para ajudar a antevisão de dificuldades que podem vir a prejudicar a implementação da reforma. Metodologias que na verdade permitem uma aferição quantitativa de uma parte importante dos riscos envolvidos na proposta.

Já há algum tempo, o desenvolvimento de métodos numéricos e o crescimento da capacidade de processamento computacional vêm revolucionando as técnicas de análise quantitativa de risco em várias áreas, da engenharia ao sistema financeiro. É apenas natural que estas técnicas sejam aplicadas à análise de propostas de modificação de políticas públicas. Um modelo de simulação baseado neste tipo de metodologia permite que se fuja da camisa-de-força imposta pelo número limitado de cenários e pela estreiteza intrínseca dos exercícios tradicionais de análise de sensibilidade. Em vez de se considerarem apenas dois ou três valores possíveis para uma variável ou parâmetro de valor incerto, pode-se trabalhar com toda uma distribuição de probabilidade desta variável ou parâmetro, de forma a explicitar de maneira mais clara a incerteza envolvida na sua determinação, tendo em vista a melhor avaliação, ainda que subjetiva, do especialista. Mais ainda, a incerteza sobre as diversas variáveis e parâmetros intervenientes no processo pode ser conjuntamente considerada na análise. Lançando mão de técnicas conhecidas como simulações de Monte Carlo, tais modelos, através de milhares de iterações, cada uma delas representando um cenário diferente, conseguem gerar não apenas um valor para cada variável endógena, mas uma distribuição para cada uma destas variáveis. E isto permite aferir de forma muito menos impressionista o risco de que o valor de uma dada variável não atinja, por exemplo, uma determinada marca crucial na decisão envolvida.

É fácil perceber a utilidade dessa metodologia para o estudo da proposta de reforma tributária, quando se constata o elevado grau de incerteza que cerca algu- 
mas das variáveis que deverão ter um papel fundamental na determinação de seus desdobramentos. Face ao alto nível de incerteza, análises tradicionais, baseadas em valores médios plausíveis para os diversos parâmetros e variáveis relevantes, estão fadadas a lançar menos luz do que seria desejável sobre a extensão dos riscos em jogo. Em vista destas limitações, a análise que se segue recorre a simulações de Monte Carlo e outros métodos para analisar os desdobramentos da incerteza que cerca algumas das variáveis envolvidas nas equações [19] e [27] acima.

Como bem evidenciado nas seções anteriores, um papel crítico deverá caber à variável $\alpha_{I V A}$. Para que o novo imposto sobre valor adicionado gere a receita dele requerida com uma alíquota razoavelmente baixa, é essencial que o IVA seja implantado como um tributo de base realmente ampla. Embora, em princípio, nada impeça que o governo proponha uma abrangência bastante ampla da definição legal da base do imposto, não deve ser subestimada a intensidade da oposição que uma proposta deste tipo terá de enfrentar no Legislativo. Para que a base do IVA seja suficientemente ampla, a atual base do ICMS terá que ser estendida em muito, especialmente no sentido de passar a abranger a maior parte dos setores produtores de serviços que, em geral, vêm sendo mantidos ao abrigo de uma tributação significativa através de impostos indiretos explícitos. Tudo indica que uma mudança neste sentido deverá ter de lidar com forte resistência no Legislativo. Por outro lado, a ampliação da base de tributação do valor adicionado deverá também exigir que este passe a gravar de forma mais efetiva um grande número de produtos e serviços usualmente considerados de consumo essencial ou meritório. Tampouco será pequena a oposição, no Legislativo, a um movimento neste sentido.

É inevitável, portanto, que se formem poderosas e complexas coalizações no Congresso em torno da aprovação de modificações da proposta do governo que, por vias variadas, impliquem, em última análise, a erosão da base potencial do novo imposto. $E$ isto poderia acabar empurrando a reforma ou para a imposição de uma alíquota pouco razoável do IVA ou para a tentativa de gerar um nível despropositadamente alto de receita através do imposto seletivo. Há também que se ter em mente que, qualquer que seja a abrangência legal no imposto sobre valor adicionado que o Executivo afinal consiga extrair do Congresso, resta a incerteza sobre que grau de exploração efetiva desta base poderá afinal ser viável, dadas as limitações do aparato de fiscalização disponível.

O governo dispõe de assessoria parlamentar e especialistas competentes para avaliar corretamente as incertezas discutidas acima. O que aqui se pretende é apenas chamar a atenção para o fato de que, dada a natureza das restrições representadas pelas equações [19) e (27) acima, modificações relativamente pequenas na avaliação subjetiva dessas incertezas podem resultar em modificações muito pronunciadas nos seus desdobramentos.

Como ponto de partida, pode-se supor que o governo, plenamente consciente da necessidade de assegurar uma base efetivamente ampla ao IVA, desenhe uma proposta de reforma e uma estratégia de negociação política com o Congresso condizentes com este propósito. $\mathrm{E}$ que, com base nisto, avalie subjetivamente, por exemplo, que, embora na melhor das hipóteses o valor de $\alpha_{I V A}$ possa até chegar a 
0,9, o mais provável é que acabe sendo 0,85 . E que, na pior das hipóteses, não possa chegar a ser inferior a 0,6 . Para situações em que as avaliações subjetivas da incerteza envolvida se faz em termos da determinação de três valores da variável em jogo - mínimo, mais provável e máximo -, pode ser útil, para efeito de análise quantitativa de risco, recorrer à chamada distribuição de probabilidade Beta-Pert. ${ }^{4}$ A figura 6.1, abaixo, apresenta a distribuição Beta-Pert compatível com a avaliação subjetiva sobre ${ }^{a} r v A$ suposta no exemplo acima. Partindo-se inicialmente da equação [19), ou mais precisamente, da equação [20),

$$
\mathrm{t}_{\mathrm{IVA}}^{*}=\frac{\mathrm{R}-\mathrm{t}_{\mathrm{SEL}} \alpha_{\mathrm{SEL}} \mathrm{B}_{\mathrm{SEL}}-\alpha_{\mathrm{IVA}} \mathrm{B}_{\mathrm{IVA}} \Sigma \mathrm{t}_{\mathrm{j}} \alpha_{\mathrm{j}} \mathrm{b}_{\mathrm{IVA} j}}{\alpha_{\mathrm{IVA}} \mathrm{B}_{\mathrm{IVA}}\left(1+\Sigma \mathrm{t}_{\mathrm{j}} \alpha_{\mathrm{j}} \mathrm{b}_{\mathrm{IVA}}\right)}
$$

que dela se obtém, pode-se determinar, através de simulações de Monte Carlo, que distribuição teria a alíquota requerida $t_{I V A}{ }^{*}$, caso $\alpha_{I V A}$ se distribuísse como na figura 6.1.

Figura 6.1: Distribuição de Probabilidade para $\alpha_{I V A}$ Min.=0,6 Moda=0,85 Máx.=0,9

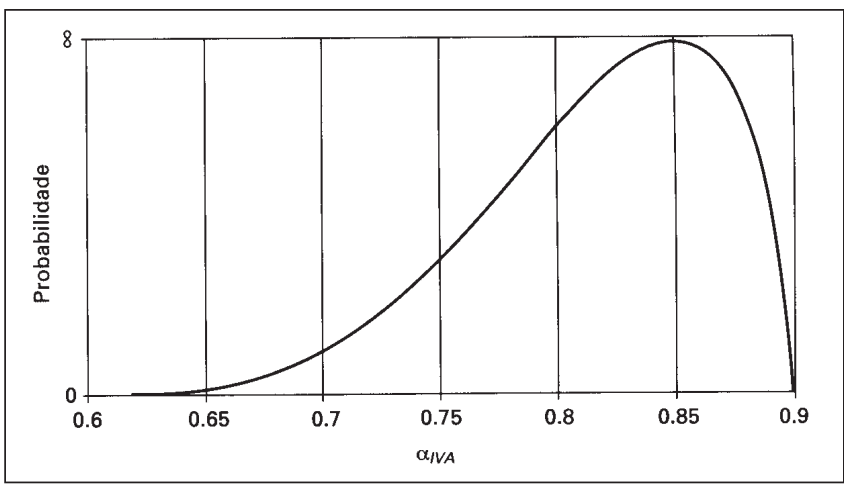

Preservando-se as hipóteses para os parâmetros envolvidos na determinação da arrecadação do IVV já apresentadas na tabela 3.3, e supondo-se uma receita do imposto seletivo SEL igual a R \$ 20 bilhões, obtém-se a distribuição para $t_{I V A}$ * apresentada na figura 6.2, abaixo. ${ }^{5}$ A título de exemplo, sob estas hipóteses, a probabilidade de que a alíquota requerida $t_{I V A}{ }^{*}$ tenha que ser maior ou igual a $18 \%$ seria $30,8 \%$, como medido pela área sob a curva, à direita deste valor.

\footnotetext{
4 Tal distribuição nada mais é do que uma distribuição Beta transformada, que permite acomodar variáveis aleatórias cujo intervalo de variação não está limitado por 0 e 1 , como na distribuição Beta.

${ }^{5} \mathrm{Na}$ verdade, o método de amostragem utilizado foi o de Hipercubo Latino, uma variante do método de Monte Carlo
} 
Pode-se agora conjugar desdobramentos da incerteza advinda de $\alpha_{I V A}$ com os que podem decorrer da incerteza sobre os valores dos parâmetros $\alpha_{j}$, que determinam o grau de aproveitamento da base do IVV nos vários "estados". Para se detectar a importância relativa destas fontes adicionais de incerteza, presumiu-se que cada um dos parâmetros a1 fosse distribuído de acordo com uma distribuição Beta-Pert,com valor mínimo idêntico ao suposto na tabela 3.3, valor mais provável igual ao mínimo mais 0,1 , e máximo igual ao mínimo mais 0,2 .

Figura 6.2 Distribuição para $t_{\text {IVA }}{ }^{*}$

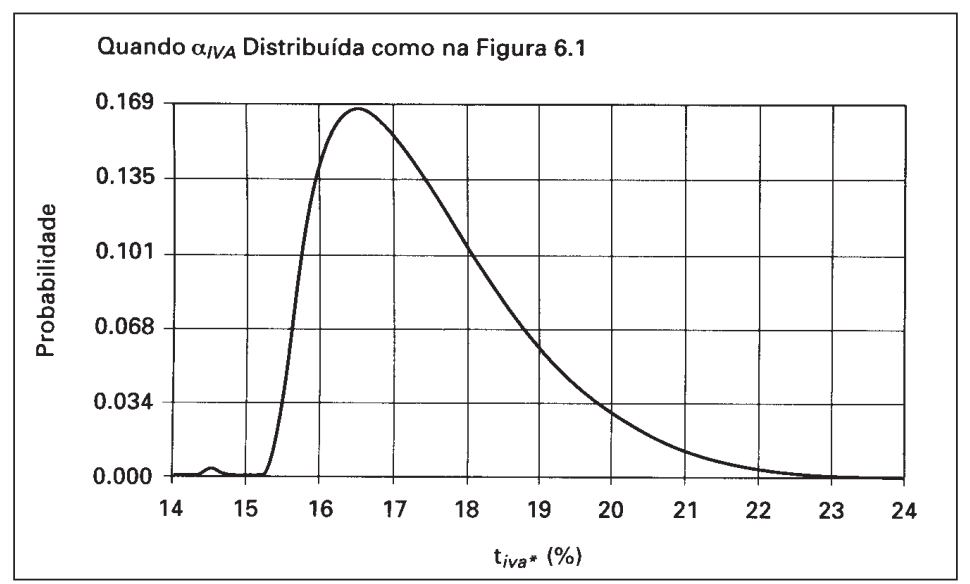

Como era de se esperar, novas simulações, feitas com base nestas hipóteses geraram uma distribuição que se posiciona à esquerda da anteriormente obtida, quando apenas a incerteza sobre $\alpha_{I V A}$ havia sido levada em conta. Mas apesar das hipóteses acerca das distribuições dos $a$ incorporarem um aumento substancial dos seus valores vis-à-vis às hipóteses adotadas na tabela 3.3, o deslocamento da distribuição parece relativamente modesto, como mostra a figura 6.3. Enquanto a média da primeira distribuição é de cerca $17,5 \%$ a da segunda é de $16,9 \%$. A comparação das duas distribuições sublinha a dominância da incerteza sobre $\alpha_{I V A}$ na determinação da distribuição da alíquota requerida $t_{I V A}{ }^{*}$. Esta constatação sugere que se prossiga a análise deixando-se de lado a preocupação com a incerteza acerca dos ai e centrando-se a atenção exclusivamente na incerteza acerca de $\alpha_{I V A}$.

Se a atenção for concentrada apenas em aIVA' presumindo-se que todas as outras variáveis envolvidas no lado direito da equação [20] têm valor conhecido, a determinação da distribuição de $t_{I V A}{ }^{*}$ pode passar a ser feita diretamente, sem maiores dificuldades. É fácil ver que a equação [20], estabelece uma função bijetora de aivA em $t t_{I V A}{ }^{*}$, cujo gráfico, aliás, já foi apresentado acima na figura 3.1 na seção 3. Assim, feita uma hipótese sobre a função de probabilidade de aivA podese imediatamente determinar a distribuição correspondente de $t_{I V A}{ }^{*}$. 


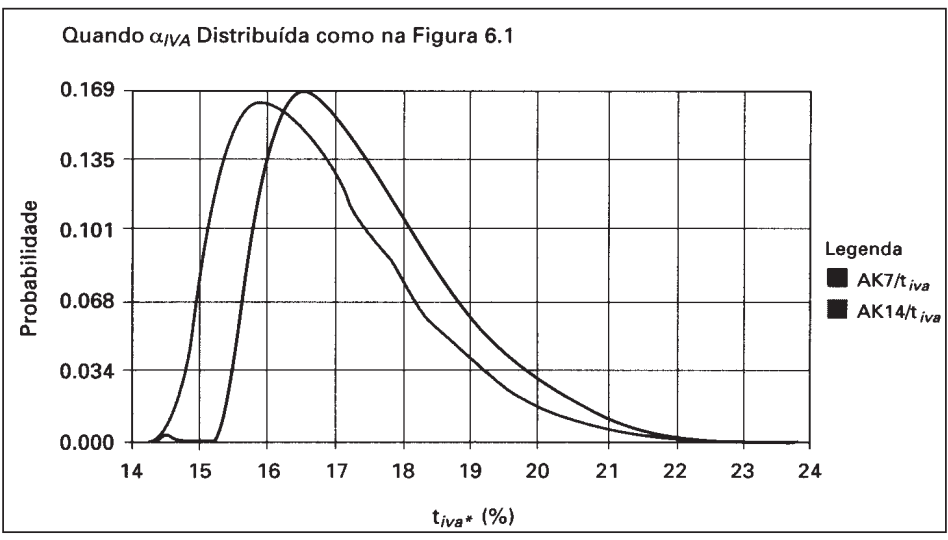

Isto pode ser útil para se avaliar a sensibilidade da distribuição de $t_{I V A}{ }^{*}$ a modificações relativamente pequenas na avaliação subjetiva do governo sobre o valor que $\alpha_{I V A}$ poderá afinal assumir. Para este efeito, a figura 6.4 apresenta duas outras distribuições Beta-Pert para aIVA além da já discutida e apresentada na figura 6.1. As duas novas distribuições têm os mesmos valores extremos presumidos na distribuição anterior mas partem de presunções um pouco mais pessimistas sobre o valor mais provável que aIVA pode assumir: 0,80 e 0,75 .

Com base da equação [20], podem ser obtidas as três distribuições correspondentes de $t_{I V A}{ }^{*}$, apresentadas na figura 6.5. São distribuições com implicações bastante diferentes. A probabilidade de que $t_{I V A}$ * tenha que superar, por exemplo, $18 \%$, dada pela área sob curva à direita desta marca, seria de 30,8\% para a distribuição mais à esquerda, $55 \%$ para a distribuição em posição intermediária, e 76,5\% para a distribuição à direita. $\mathrm{E}$ as probabilidades de que $t_{I V A}$ tenha que superar $20 \%$, seriam respectivamente de $5,8 \%, 17 \%$ e $35,7 \%$.

Nos três casos, a probabilidade de que $t_{I V A}$ * tenha que superar $25 \%$ é nula. Isto poderia ser considerado algo tranquilizador, não fosse o fato de que toda esta análise se baseia na equação [20], obtida no primeiro modelo, que não leva em conta que o grau de aproveitamento efetivo da base do IVA pode depender da alíquota imposta. Em termos do segundo modelo, é como se as distribuições obtidas na figura 6.5 presumissem que a elasticidade $v$ fosse zero. Faz sentido, portanto, verificar o que pode ocorrer com estas distribuições se $v$ assumir valores positivos.

Como pode ser visto na figura 5.1 da seção 5 , para cada valor de $v$, a raiz $t_{I V A}$ *da equação [27] é também uma função bijetora de $\alpha_{I V A}$ ' o que, novamente, torna possível determinar sem maiores dificuldades a distribuição de $t_{I V A}{ }^{*}$ a partir da distribuição de $\alpha_{I V A}$. A figura 6.6 apresenta, para diferentes hipóteses sobre o valor de elasticidade $v$, as distribuições de $t_{I V A}{ }^{*}$ correspondentes às três distribuições para ${ }^{a} i v A$ apresentadas na figura 6.4.

Pode-se notar que a variância da distribuição da alíquota requerida $t_{I V A}{ }^{*}$ cres- 
Figura 6.4:

Três Distribuições para $\alpha_{I V A}$

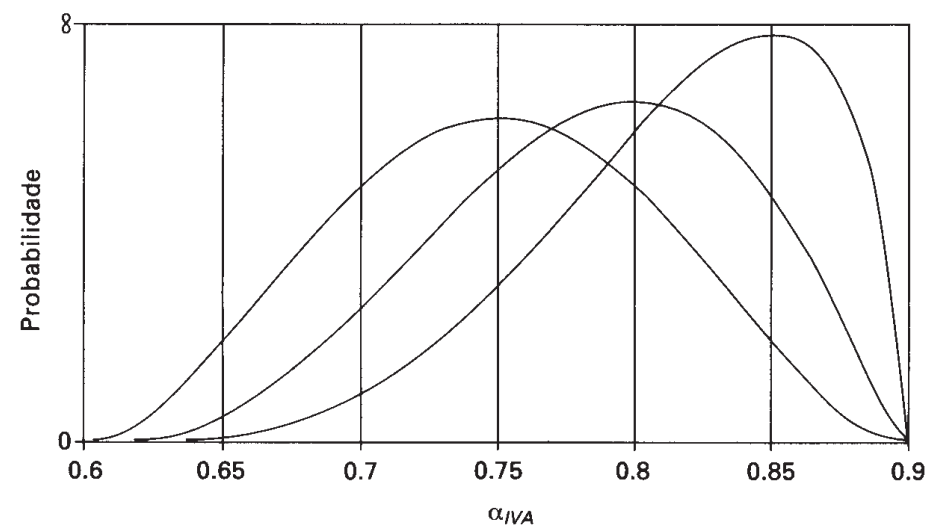

Figura 6.5:

Distribuições para $\mathrm{t}_{\mathrm{VA}}{ }^{*}$

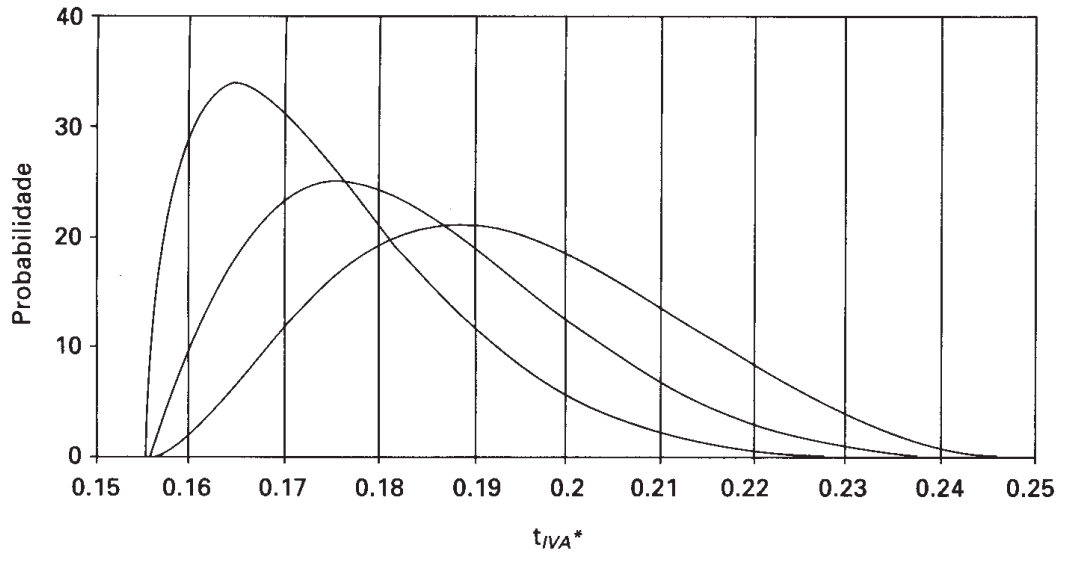

ce dramaticamente à medida que se assumem valores mais altos para $v$. $\mathrm{O}$ gráfico superior na figura 6.6, que apresenta as distribuições quando $v=0$, apenas reproduz as distribuições já apresentadas na figura 6.5. O conjunto de gráficos mostra também, de forma contundente, como uma diferença aparentemente pequena na avaliação do governo sobre que valor $\alpha_{I V A}$ poderá afinal assumir, pode fazer uma enorme diferença em termos da probabilidade de que a alíquota requerida $t_{I V A}$ " supere uma determinada marca crítica.

Para que isto pudesse ser percebido de forma ainda mais clara, deixou-se que, 
na família de distribuições para $\alpha_{I V A}$ apresentada na figura 6.4, a moda — o valor mais provável da distribuição - assumisse valores entre 0,7 5 e 0,85. E que a elasticidade $v$ variasse entre zero e 0,5 . E, para cada combinação de valores da moda e de $v$, computou-se a probabilidade de que a alíquota requerida $t_{I V A}{ }^{*}$ tivesse que ser maior ou igual a $20 \%$. A figura 6.7 apresenta os resultados destas simulações. Mostra, para diferentes valores da moda da distribuição e da elasticidade $v$, curvas de nível para a probabilidade (medida em percentagem) de que a alíquota requerida $t_{I V A}$ " tenha que ser maior ou igual a $20 \%$. Pode-se notar que quanto mais alta a moda da distribuição de $\alpha_{I V A}$ e menor a elasticidade $v$, mais baixa esta probabilidade. Para um dado valor de $v$, esta probabilidade aumenta muito rapidamente à medida que a moda decresce. Da mesma forma, para um dado valor da moda, a probabilidade aumenta rapidamente à medida que cresce o valor de $v \mathrm{Na}$ parte superior esquerda do gráfico, a probabilidade de que a alíquota supere $20 \%$ torna-se extremamente alta.

A análise permite concluir que, para levar adiante a proposta de reforma, o governo tem de estar se sentindo capaz de preservar a todo o custo, no Congresso,

a ideia de uma base efetivamente ampla para o IVA. Quanto mais alta a probabilidade de que isto possa ser assegurado, menor o risco de que a reforma venha a exigir a imposição de uma alíquota excessivamente alta do imposto sobre valor adicionado. O que comprometeria o que de melhor se pode esperar da proposta.

\section{COMENTÁRIOS FINAIS}

Em termos muito simples, o desafio a ser enfrentado pela reforma é conseguir gerar cerca de R 108 bilhões, que hoje são gerados através de impostos de baixa qualidade - cuja extinção está sendo contemplada - com três novos impostos de melhor qualidade. É inevitável que o papel central na arrecadação desta massa de recursos tenha que recair sobre o novo imposto sobre valor adicionado. A arrecadação do atual ICMS foi da ordem de R \$ 60 bilhões em 1997. Com o desaparecimento da COFINS e do PIS-PASEP, que arrecadaram quase R 27 bilhões no ano passado, o IVA teria que contribuir com bem mais do que a atual arrecadação do ICMS para que não houvesse perda de receita. Possivelmente, como mostraram as simulações analisadas acima, com pelo menos $\mathrm{R} \$ 10$ ou 15 bilhões a mais. Ou mais ainda, talvez, dependendo da receita que puder ser extraída do IVV, que no fundo seria apenas uma sobretaxa do IVA, cobrada pelas esferas infranacionais de governo, quase certamente com menos eficiência.

O sentido da reforma parece fundamentalmente correto. Mas, como se procurou enfatizar acima, a sua viabilidade deverá depender em boa medida da possibilidade de se implantar um imposto sobre valor adicionado de base efetivamente ampla. Parece não haver outra forma de se conseguir gerar o montante requerido de recursos, ainda que a batalha política em torno da definição de uma base ampla para o IVA prometa ser difícil. Vale aqui uma relação de mão dupla. De um lado, 
Figura 6.6:

Distribuições da Alíquota Requerida $\mathrm{t}_{\text {IVA }}{ }^{*}$ para Diferentes Valores de $\mathrm{v}$
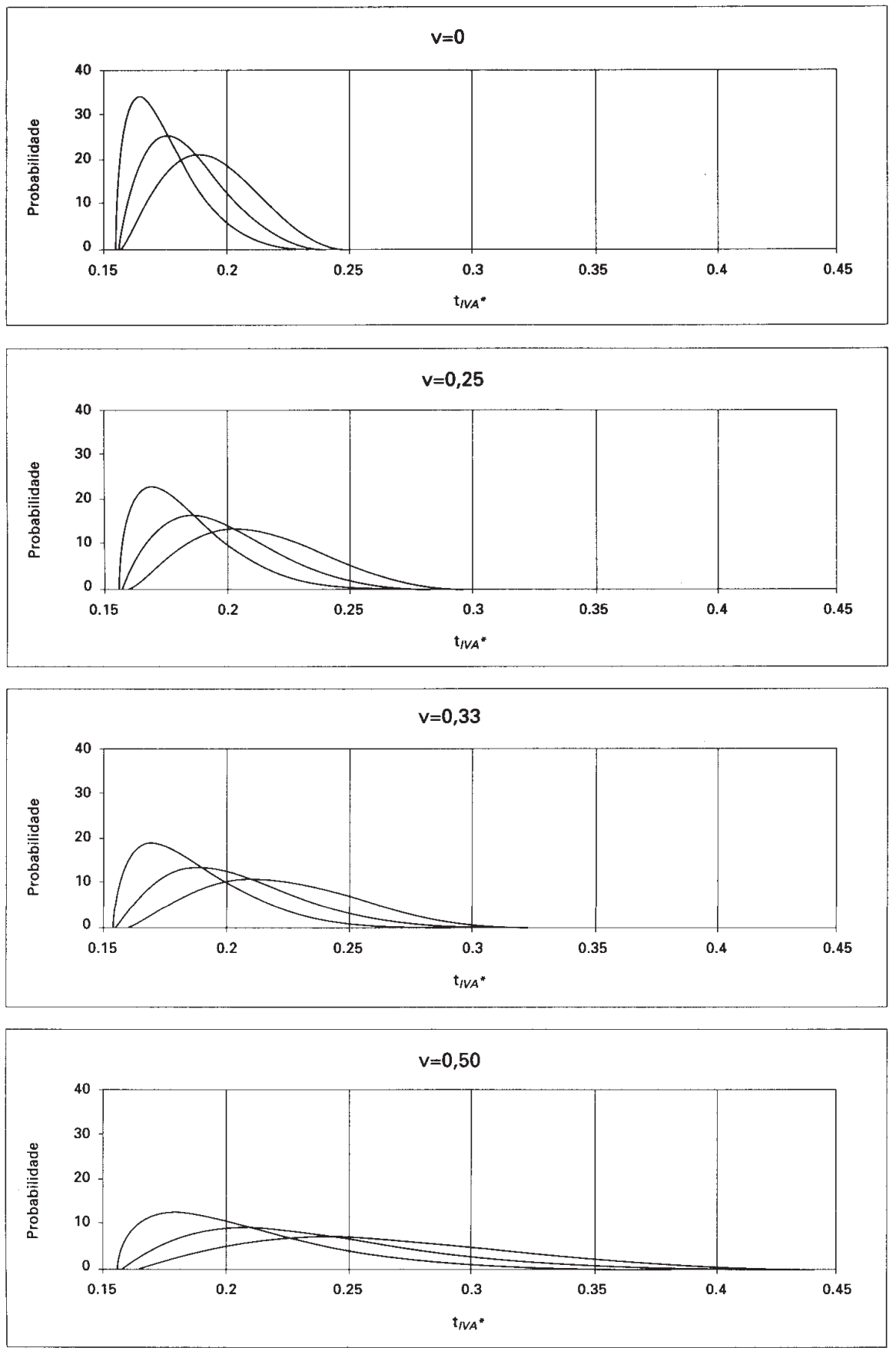
Figura 6.7: Probabilidade (\%) de que a Alíquota Requerida $t_{/ V A}{ }^{*} \geq 20 \%$ Curvas de Nível para Diferentes Valores de v e da Moda da Distribuição de $\alpha_{I V A}$

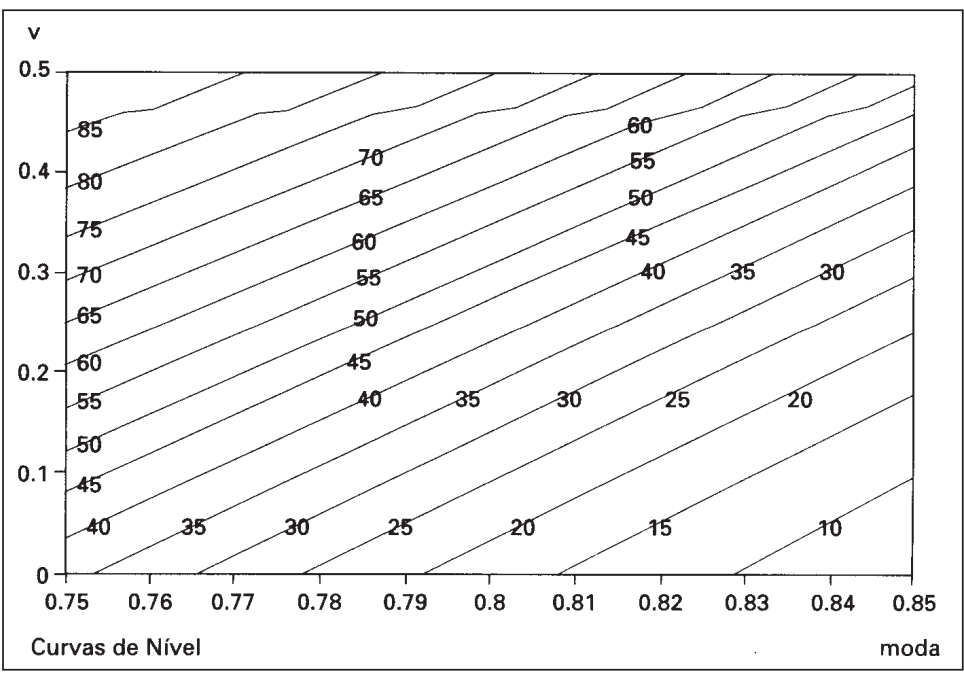

a base deve ser ampla para que a alíquota possa ser baixa. De outro, se a alíquota for alta, não será possível contar na prática com uma base ampla, mesmo que a definição legal da base possa parecer ampla.

Outro ponto fundamental é que a proposta precisa avançar com cuidado no desenho do rearranjo federativo. A transformação do ICMS em um imposto nacional sobre valor adicionado, administrado pelo governo federal, é mais do que defensável, mas deixaria os estados sem sua principal fonte de receita própria. É verdade que isto não precisa significar perda para os estados. E que é perfeitamente possível conceber um sistema de compensações na linha que vem sendo aventada pelo governo. Mas, mesmo que nenhum estado venha a ter qualquer perda, a repartição da massa de recursos fiscais envolvidos na reforma seria alterada de tal forma que, muitos estados - especialmente os das regiões Sul, Sudeste e Centro Oeste - passariam de uma posição de doador líquido para outra de receptador líquido de recursos. ${ }^{6}$ Do ponto de vista puramente aritmético, isto pode não ter importância, já que não haveria perda líquida para qualquer estado. Mas, do ponto de vista político, pode ter uma importância fundamental. Parece haver em alguns estados o sentimento de que é preferível ser um doador líquido de recursos fiscais. A maior parte dos governadores parece tirar bom proveito político da administra-

\footnotetext{
${ }^{6}$ Isto é claramente evidenciado quando se comparam os resultados das simulações apresentados no gráfico 8 da figura $3.3 \mathrm{com}$ as colunas intermediárias da tabela 3.2, que apresentam os fluxos atuais de transferência, entre as várias esferas de governo, dos recursos que estariam envolvidos na reforma.
} 
ção das liberações do fundo de participação dos municípios e ver com bons olhos pouca dependência de recursos federais.

Para quebrar este tipo de resistência, talvez seja importante dar à redistribuição dos recursos fiscais, envolvidos na reforma, um grau de automatismo suficientemente alto para que os estados passem a perceber a participação no IVA nacional mais como receita própria do que como simples transferências federais.

\section{REFERÊNCIAS}

CNI, Confederação Nacional da Indústria (1998). Anais do Seminário de Reforma Tributária. Rio de Janeiro: CNI, Unidade de Política Econômica (PEC). 